\title{
MODELING OF COMPRESSION ENGINES USING BIODIESEL AS
}

\section{FUEL}

\author{
A. Samanta ${ }^{1}$, S. Kumar ${ }^{2}$, P. C. Roy $^{3}$ \\ ${ }^{1}$ Assistant Professor, Mechanical Engineering Department, BBIT, West Bengal, India \\ ${ }^{2}$ Student, Mechanical Engineering Department, Jadavpur University, West Bengal, India \\ ${ }^{3}$ Assistant Professor, Mechanical Engineering Department, Jadavpur University, West Bengal, India
}

\begin{abstract}
A single zone C.I engine model has been developed in an in-house code that would be suitable for conventional diesel as well as for alternative fuel (biodiesels), to predict the pressure and temperature variation along crank angle, work done, mean effective pressure, power output and other engine parameters suitable for biodiesel. The model has been validated with the experimental results. Performance of the diesel engine depends on injection timing, delay period as well as the duration to get complete combustion are presented and discussed. The indicated and brake work done obtained are $13.20 \mathrm{~kJ} / \mathrm{cycle}$ and $10.52 \mathrm{~kJ} / \mathrm{cycle}$ respectively for $B 100$ and the indicated and brake specific fuel consumption obtained are $0.289 \mathrm{~kg} / \mathrm{kWh}$ and $0.362 \mathrm{~kg} / \mathrm{kWh}$.
\end{abstract}

Key Words: Biodiesel, Biodiesel engine, engine model.

\section{INTRODUCTION}

Most of the developments in automotive engines were to improve the power and fuel economy as well as to reduce the environmental pollutant for conventional fuel. But now there is a call for stringent environmental issue and fuel crisis in world wide. Composition and quality of conventional fuel is not widely varied since it is obtained from petroleum source after refinement. But it is frequently for alternative fuels which are obtained from different sources and processes. So there is challenge to adopt adequate development of the engine, which is suitable for alternative fuels which may be varied with its composition as well as heating value. The development of I.C. engine was not an easy task as its performance is depended on number of factors such as fuel compositions, heating value, combustion characteristics as well engine design and other features. The built and test method of the engine is not suitable due to its high cost and time consuming. So many scientists and engineers adopted another methodology which is the modeling approach based on the thermodynamics, fluid flow and heat transfer to predict the engine performance. Actual combustion phenomena are very much complex but it can be simplified by taking some assumptions The use of alternative fuels considerably decreases harmful exhaust emissions as well as ozoneproducing emissions. Alternative fuels can be less expensive to use not just in terms of the fuel itself but also in terms of a longer service life. Lot of research have been done on the performance on the engine using alternative fuel [1-9]. Ramadhas et al. [1] developed a thermodynamic model to analyze the performance characteristics of the CI engine fueled by biodiesel and its blends and concluded that with the increase in compression ratio peak pressure, peak temperature and brake thermal efficiency are increased. Gogoi and Baruah [2] developed a single zone combustion model to predict the performance of diesel engine. The effect of engine speed and compression ratio on brake power and brake thermal efficiency is analyzed through the model. Lesnik et al. [3] carried out an experiment and numerical analysis on a heavy-duty bus diesel engine using mineral diesel fuel, neat biodiesel fuel and concluded that a reduction in engine power and torque when increasing the percentage of biodiesel fuel in the fuel blends due to lower calorific value of biodiesel fuel. Samanta [4] developed a single zone, thermodynamic model of internal combustion engine using biogas as chemical energy source and the effects of different parameters were investigated and optimization points were identified for the computational engine model. Abou Al-Sood et al. [5] developed a thermodynamic model for the evaluation of the performance of the four stroke DI diesel engine. The model was validated with experimental and predicted results for different engines operating at different conditions. Awad et al.[6] proposed a unique single zone combustion model for diesel fuel and biodiesel to predict the cylinder pressure for the better understanding of combustion characteristics. Lata and Misra [7] developed a mathematical model to predict pressure, net heat release rate, mean gas temperature, and brake thermal efficiency for dual fuel diesel engine operated on hydrogen, LPG and mixture of LPG and hydrogen as secondary fuels. Pyari et al. [8] developed a single zone thermodynamic model that takes into account the heat transfer to the chamber walls, the blow-by leakage, the fuel injection and engine deformations, along with the instantaneous change in gas properties. The model was validated in different operation points and showed a good capability for accurate predictions of engine performance. Ganapathy et al.[9] developed a two zone thermodynamic model for the analysis of Jatropha biodiesel engine to determine the optimum engine design and operating parameters. To maximize the performance of Jatropha biodiesel engine the signal to noise 
ratio (SNR) related to higher-the-better (HTB) quality characteristics has been used.

In the present work a single zone thermodynamic model has been developed which is built coupled with number of submodels for conventional fuel and applied for biodiesel based on law of conservation of energy, energy release rate and equation of state. Among the sub models, the ignition delay model is same as that of Stone [10] and heat transfer model is not considered in the present work. In the present work, effect of suction and exhaust stroke have been incorporated in the intake and exhaust model. Also effects of friction losses at the different parts of the engines have been taken care of in the frictional loss model. Model predicted results have been validated with the experimental data as well as by the numerical data reported by Ramadhas et al.[1].

\subsection{Model Descriptions}

A thermodynamic model of the compression ignition engine (C.I. Engine) based on single zone [11] approach considering different sub-models and the variations of specific heats with local temperature [Abu Nada et al.[12]. Heat transfer loss from the engine has been considered as percentage heat leakage from the engine [13]. The following assumptions have been taken to develop for the actual cyclic operation of the C.I. Engines.

- The air inside the cylinder and the combustion product mixture are assumed to be homogenous and ideal gas.

- Inside the combustion chamber chemical equilibrium exist among the gaseous species.

- The specific heats of the gaseous species vary with the local temperature.

- The variations of the specific heats have been considered with the change in the crank rotation due to change in temperature and condition.

- The suction, compression, expansion and exhaust stroke of engine cycle are considered.

- Combustion chamber design has no effects in the engine model.

- At the compression stroke the initial pressure is assumed to be atmospheric pressure.

- The heat release model has been developed using ignition delay, pressure and temperature at ignition delay and equivalence ratio.

- Inlet valve and the exhaust valve open and close at BDC only.

- Heat loss from the considered as a percentage of fuel loss from the cycle.

The relationship between the cylinder volume and the crank angle is the function of compression ratio, bore, stroke and connecting rod length. Combustion model has been developed based on the conservation principle applied to a combustion chamber as the control volume. The relation from ideal gas law and its differential form,

$$
P V=m R_{g} T \quad \text { and } \frac{d V}{V}+\frac{d P}{P}=\frac{d T}{T}
$$

The relation from conservation of energy can be expressed in differential form and applied to a control volume. The equation becomes for net heat release rate is

$$
\frac{d Q_{n}}{d \theta}=m c_{v} \frac{d T}{d \theta}+P \frac{d V}{d \theta}
$$

Rearranging equations ( 1 and 2 )

$$
\frac{d P}{d \theta}=\frac{k-1}{V} \frac{d Q_{n}}{d \theta}-\frac{k P}{V} \frac{d V}{d \theta}
$$

The net heat term has both heat added and heat loss in case of combustion

$Q_{n}=Q_{i n} x_{b}-Q_{l}$ Where, $Q_{\text {in }}$ indicates total heat input and $x_{b}$ as fraction of heat release, The heat loss can be obtained as,

$\frac{d Q_{l}}{d \theta}=\frac{h_{g}(\theta) A_{w}(\theta)}{\omega}\left(T_{w}-T_{g}(\theta)\right)$

According to Rakapoulos [14] the temperature of wall can be taken as constant. In the present work the ratio of temperature is taken as $T_{w} / T_{1}=1.2$

The mass fraction of fuel burned in an internal combustion engine can be expressed as a function of crank angle using the Wiebe function,

$x_{b}(\theta)=1-\exp \left\{-a\left(\frac{\theta-\theta_{s}}{\Delta \theta}\right)^{n}\right\}$

(5)

Now, according to Stone [10]

$x_{b}=\alpha f_{1}(\lambda)+(1-\alpha) f_{2}(\lambda)$

$\alpha$ =pre-mixed diffusion combustion parameter for compression ignition engine,

$f_{1}(\lambda)=$ pre-mixed phase, $f_{2}(\lambda)=$ diffusion burning phase $\alpha=1-0.875 \frac{\phi^{0.350}}{\tau^{0.375}}$

Now, $\quad \tau \quad, \phi$ =equivalence ratio.

Ignition delay is the time taken to start the combustion after the injection of the fuel. For the calculation of ignition delay many expressions were found in literature as a function of pressure, temperature, cetane number and equivalence ratio. The following empirical relation is used for the calculation of ignition delay [14].

$\tau=\frac{3.52 \exp \left(2100 / T_{i d}\right)}{\left(p_{i d} / 100\right)^{1.022}}$

$\tau$ =ignition delay, $T_{i d}=$ temperature at ignition delay $=T_{i d}=T_{1} r_{c}^{k-1}, \quad p_{i d}=$ pressure at ignition delay $p_{i d}=p_{1} r_{c}^{k}$.

Here, $k=$ adiabatic index $=\frac{c_{p}}{c_{v}}$

So, $\frac{d x_{b}}{d \theta}=\frac{\alpha}{\Delta \theta} \frac{d f_{1}}{d \lambda}+\frac{1-\alpha}{\Delta \theta} \frac{d f_{2}}{d \lambda}$

So, the heat release and mass burn fraction are related as $\frac{d Q_{n e t}}{d \theta}=Q_{i n} \frac{d x_{b}}{d \theta}-$ loss 
Net heat input ( $Q_{\text {in }}$ ) can be expressed as

$$
Q_{\text {in }}=V_{f} \eta_{v} Q_{L H V}
$$

Where, $V_{f}$ is the volume of fuel inside the combustion chamber, $\eta_{v}$ is the volumetric efficiency and $Q_{L H V}$ is the lower heating value of fuel.

The final relation of combustion chamber pressure with the crank angle is obtained as

$\frac{d P}{d \theta}=\frac{k-1}{V}\left[Q_{i n} \frac{d x_{b}}{d \theta}-\frac{h_{g}(\theta) A_{w}(\theta)}{\omega}\left(T_{w}-T_{g}(\theta)\right)\right]-\frac{k P}{V} \frac{d V}{d \theta}$

The above equation is solved by using explicit finite difference technique with second - order accuracy as [12].

The pressure variation during the intake and exhaust stroke can be obtained as [15]:

$$
\frac{d P}{d t}=k P\left(\frac{1}{M} \frac{d M}{d t}-\frac{1}{V} \frac{d V}{d t}\right)
$$

The equation (9) requires mass flow rate $d M / d t$, which is to be found from the equations of fluid mechanics. For the intake stroke, mass flow rate can be obtained as :

$$
\begin{aligned}
\frac{d M_{i n}}{d t} & =A P \sqrt{\frac{2 k}{R T(k-1)}\left(\frac{P_{i n}}{P}\right)^{\frac{k-1}{k}}\left[\left(\frac{P_{i n}}{P}\right)^{\frac{k-1}{k}}-1\right]} \\
\frac{d M_{i n}}{d t} & =A P \sqrt{\frac{k}{R T}\left(\frac{2}{k+1}\right)^{(k+1) /(k-1)}}[(\mathrm{Pin} / \mathrm{P})>\mathrm{PRcric}]
\end{aligned}
$$

The critical pressure ratio that defines the two regimes is called $P R_{\text {crit }}$ and depends only on the value of $k$ of the gas.

$$
P R_{\text {crit }}=\left(\frac{k+1}{2}\right)^{\frac{k}{k-1}}
$$

Where $\boldsymbol{P}_{i n}$ the intake manifold pressure and $\mathrm{P}$ is is the cylinder pressure.

Similarly for the exhaust stroke there is a little change in the mass flow rate equation which is mentioned below.

$$
\begin{aligned}
& \frac{d M_{e x}}{d t}=A P \sqrt{\frac{2 k}{R T(k-1)}\left(\frac{P}{P_{e x}}\right)^{\frac{k-1}{k}}\left[\left(\frac{P}{P_{e x}}\right)^{\frac{k-1}{k}}-1\right]} \\
& \frac{d M_{e x}}{d t}=A P \sqrt{\frac{k}{R T}\left(\frac{2}{k+1}\right)^{(k+1) /(k-1)}}
\end{aligned}
$$

[When (P/Pex) $>$ PRcrit]

Where $P_{e x}$ is the exhaust manifold pressure and $\mathrm{P}$ is the cylinder pressure.

Where valve area can be obtained as:

$$
A=A_{\text {in }}(|\sin \theta|)^{1 / 3}
$$

Where $A_{i n}$ is the wide-open valve area. In this model the value of $A_{i n}$ has been taken as $3.5 \mathrm{~cm} 2$ [15].

The mean effective losses of power due to friction in different moving parts are calculated by using the following empirical relations by Gogoi[12].

i) Mean effective pressure (MEP) lost due to friction in the piston and rings
$F M E P 1=12.85 * \frac{P_{s l}}{B * S} * \frac{100 * U p e}{1000}$

Where, $P_{s l}$ is the piston skirt length ( 0.65 to 0.85 times of Bore) [13], B is the cylinder bore ( $\mathrm{m}), \mathrm{S}$ is the stroke length (m) and Upe is the mean piston speed $(\mathrm{m} / \mathrm{s})$.

ii) MEP lost in bearing friction

$F M E P 2=0.0564 * \frac{B}{S} * \frac{N}{1000}$

Where, $\mathrm{N}$ is the engine speed in $\mathrm{rpm}$.

iii) Mean effective pressure (MEP) absorbed in overcome friction due to the valve gear

$F M E P 3=0.226 *\left(30-\frac{4 N}{1000}\right) * \frac{G * D v i^{1.75}}{B^{2} * S}$

Where $G$ is the number of intake valves per cylinder and $D_{v i}$ is the diameter of the intake valve.

iv) MEP lost in pumping

$F M E P 4=0.0275 *\left(\frac{N}{1000}\right)^{1.5}$

v) MEP lost in friction due to the wall tension of rings $F M E P 5=\frac{10 * 0.377 * S * n_{p r}}{B^{2}}$

Where, ${ }^{n} p r$ is the number of rings.

In this model, two rings have been considered.

vi) MEP lost in overcoming combustion chamber and wall pumping losses

FMEP6 $=\sqrt{\frac{p_{\text {imep }}}{11.45}} * 0.0915 *\left(\frac{N}{1000}\right)^{1.5}$

Where $p_{\text {imep }}$ is the indicated mean effective pressure.

The total mean effective pressure (MEP) lost in pressure can be calculated as,

$\mathrm{FMEP}=(\mathrm{FMEP} 1+\mathrm{FMEP} 2+\mathrm{FMEP} 3+\mathrm{FMEP} 4+\mathrm{FMEP} 5+\mathrm{FME}$ P6)

The specific heat ratio is the most important thermodynamic factor in calculation of the heat release in the engine. The variation of specific heats of air is found in literature [12], it was calculated by the following equation.

$C_{p}=2.506 \times 10^{-11} T^{2}+1.454 \times 10^{-7} T^{1.5}-4.246 \times 10^{-7} T+3.162 \times 10^{-5} T^{0.5}+1.3303$

$-1.512 \times 10^{4} T^{-1.5}+3.063 \times 10^{5} T^{-2}-2.212 \times 10^{7} T^{-3}$

\section{MODEL VALIDATION AND PERFORMANCE}

\section{ANALYSIS}

The results predicted by the developed model are compared with the experimental and numerical data reported by [1]. The parameters in Table 1 are given for the compression ignition engine model and have been compared with the experimental and numerical results published by [1], in his experimental report he carried out experiment on a four stroke, direct injection, and naturally aspirated single cylinder diesel engine. The specifications of the engine along with the operating conditions are given in the table 1 . 
Table -1: Engine specifications along with operating parameters [1]

\begin{tabular}{|l|l|}
\hline Engine specifications \\
\hline Type & $\begin{array}{l}\text { Four stroke, single cylinder, Compression } \\
\text { ignition engine }\end{array}$ \\
\hline Fuel & $\begin{array}{l}\text { Biodiesel }(\mathrm{B} 100) \text { of rubber seed oil methyl } \\
\text { ester }\end{array}$ \\
\hline Bore $\times$ Stroke & $0.088 \mathrm{~m} \times 0.110 \mathrm{~m}$ \\
\hline R.P.M & 1500 \\
\hline $\begin{array}{l}\text { Equivalence } \\
\text { Ratio }\end{array}$ & 0.50 \\
\hline $\begin{array}{l}\text { Compression } \\
\text { ratio }\end{array}$ & $16.5,17.5,18.5($ CI version $)$ \\
\hline
\end{tabular}

The experimental test and the numerical analysis were carried out in compression ignition engine using B100 biodiesel as a fuel and the test were carried out on three compression ratio $16.5,17.5$ and 18.5. The calorific value of the B100 fuel is $36.50 \mathrm{MJ} / \mathrm{kg}$. The pressure variation along the crank angle predicted by the developed model validated with the results obtained by [1] for different values of compression ratio (CR) at equivalence ratio 0.50 have been presented below.

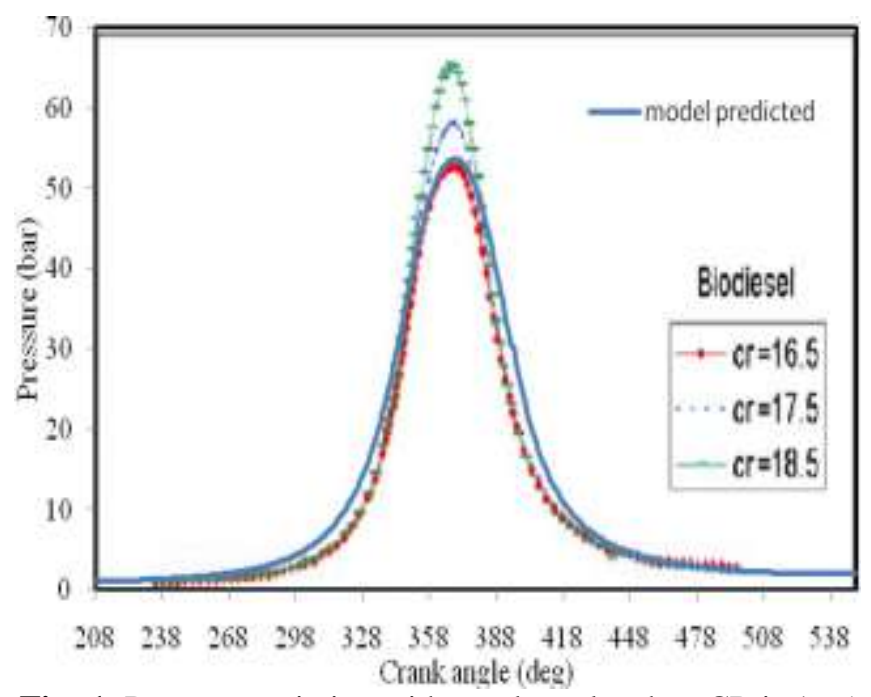

Fig -1: Pressure variation with crank angle when CR is 16.5 and the burning duration is $49^{\circ}$
Figure 1 shows the variation of the pressure with respect to crank angle when the compression ratio is 16.5 , the burning duration is 490 and the fuel injection timing is 120 BTDC (Before Top Dead Centre).

It is observed from the results shown in Figure that the variation pressure along with the crank angle are approximately same with the numerical data reported by [1] for different values of compression ratio. Therefore, the developed model can well interpret the performance parameters of the engine very well.

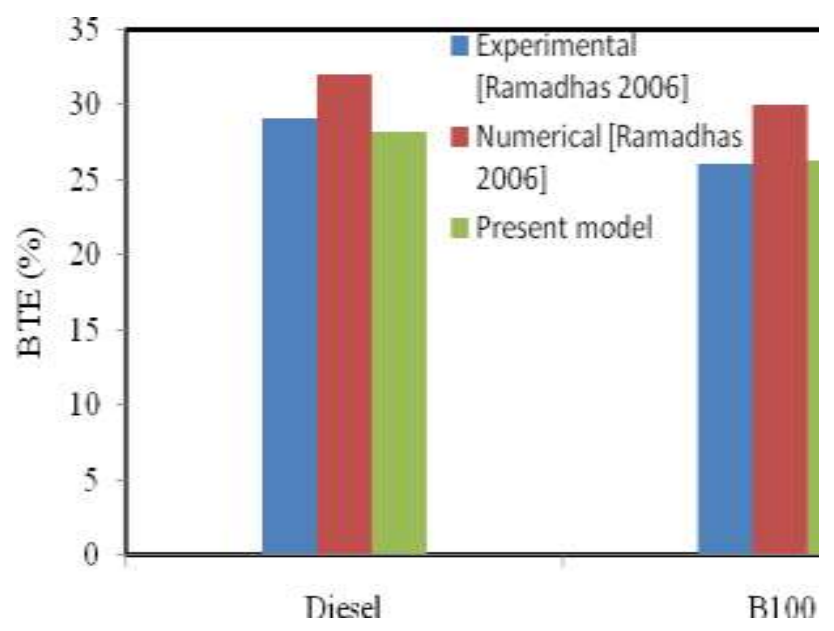

Fig -2: Comparison of brake thermal efficiency for different fuels

The present model has been validated with the experimental and numerical result for diesel and biodiesel (B100). The fig. 2 shows the brake thermal efficiency for diesel and biodiesel and here the present model result is successfully validated with the numerical and experimental results reported by [1]. Furthermore, validations of the other numerical data have been done in the table 2. It shows a reasonable agreement with the numerical data reported by [1].

Table -2: Engine other parameters compared with numerical data

\begin{tabular}{|l|l|c|c|c|}
\hline \multirow{2}{*}{ Compres-sion ratio } & & Peak Pressure (bar) & BTE (\%) & Peak Temperature (K) \\
\hline 16.5 & Present Model & 45 & 26.26 & 1353 \\
\hline 17.5 & Ramadhas et al. Model & 50 & 29 & 1420 \\
\hline & Present Model & 59 & 27 & 1360 \\
\hline 18.5 & Ramadhas et al. Model & 55 & 30.5 & 1425 \\
\hline & Present Model & 68 & 27.8 & 1386 \\
\hline
\end{tabular}


The optimization of the single zone compression engine has been done at burning duration of 440 crank angle and for the combustion start timing at 200 BTDC with an equivalence ratio of 0.5 and compression ratio 16 . The fig. 3 , shows the variation of the temperature and pressure with respect to crank angle. The maximum temperature of $1390.99 \mathrm{~K}$ is obtained at 190 ATDC and the peak pressure of 60.60 bar is obtained at 100 ATDC.

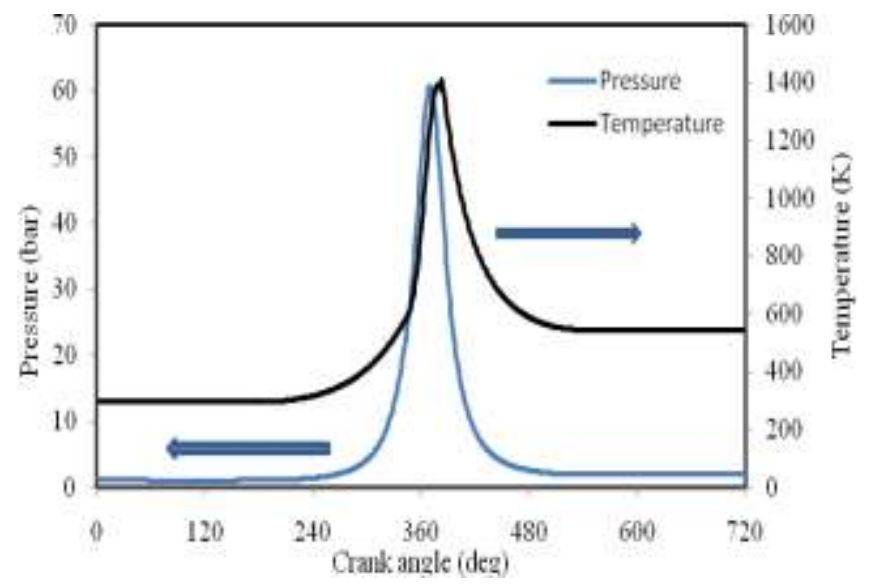

Fig -3: Temperature and Pressure variation along the crank angle

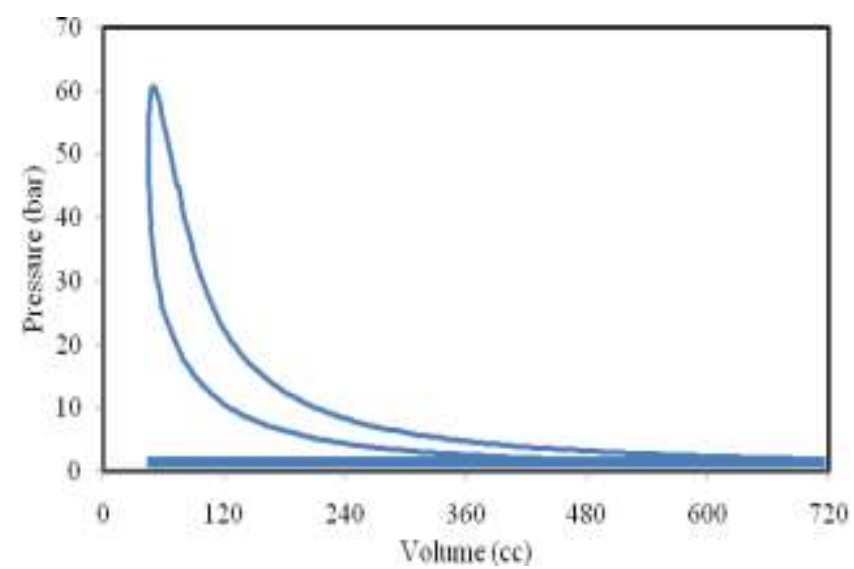

Fig -4: PV work done per cycle

Figure 4, shows the variation of pressure within the combustion chamber with respect to volume. The indicated work done is $13.20 \mathrm{~kJ} /$ cycle, the indicated thermal efficiency is $34.17 \%$ with the indicated specific fuel consumption of $0.289 \mathrm{~kg} / \mathrm{kW}-\mathrm{h}$. Also found that the indicated mean effective pressure as 5.26 bar and brake mean effective pressure as 4.18 bar. The brake work done is $10.52 \mathrm{~kJ} /$ cycle, the brake thermal efficiency is $27.21 \%$ and the brake specific fuel consumption is $0.362 \mathrm{~kg} / \mathrm{kWh}$.

\section{CONCLUSIONS}

A single zone C.I engine model based on physical geometries has been developed that would be suitable for conventional diesel as well as for alternative fuel (biodiesels). The model has been successfully validated with the simulation results as well as the experimental results available in the literature. A close agreement has obtained for different performance parameters. Optimization of the different operating parameters such as injection timing, burning duration and compression ratio have been done based on the maximum thermal efficiency and minimum fuel consumption. For Biodiesel (B100) the optimum operating conditions are $44^{\circ}$ burning duration, $20^{\circ}$ BTDC injection timing and 16 compression ratio. The value of different parameters that have been obtained under the optimum conditions. The indicated and brake work done obtained are $13.20 \mathrm{~kJ} /$ cycle and $10.52 \mathrm{~kJ} /$ cycle respectively for B100. The indicated and brake thermal efficiency obtained are $34.17 \%$ and $27.21 \%$ respectively for B100. The indicated and brake specific fuel consumption obtained are $0.289 \mathrm{~kg} / \mathrm{kWh}$ and $0.362 \mathrm{~kg} / \mathrm{kWh}$.

\section{REFERENCES}

[1]. Ramadhas, A. S., Jayaraj, S. and Muraleedharan, C., 2006, "Theoretical modeling and experimental studies on biodiesel-fueled engine", Renewable Energy, 31, pp.1813-1826.

[2]. Gogoi, T. K. and Baruah, D. C., 2010, "A cycle simulation model for predicting the performance of a diesel engine fuelled by diesel and biodiesel blends", Energy, 35, pp.1317-1323.

[3]. Lesnik, L., Iljaz, J., Hribernik, A. and Kegl, B., 2014, "Numerical and experimental study of combustion, performance and emission characteristics of a heavyduty DI diesel engine running on diesel, biodiesel and their blends", Energy Conversion and Management, 81, pp. 534-546.

[4]. Samanta, A., 2014, "Thermodynamic Modeling of Biogas fueled Automotive Engines", ME Thesis, Jadavpur University, Kolkata.

[5]. Abou Al-Sood, M. M., Ahmed, M. and Abdel-Rahim, Y. M., 2012, "Rapid thermodynamic simulation model for optimum performance of a four-stroke, directinjection, and variable-compression-ratio diesel engine", International Journal of Energy and Environmental Engineering, 3, pp. 1-13.

[6]. Awad, S., Varuvel, E. G., Loubar, K. and Tazerout, M., 2013, "Single zone combustion modeling of biodiesel from wastes in diesel engine", Fuel, 106, pp. 558-568.

[7]. Lata, D. B. and Misra, A., 2010, "Theoretical and experimental investigations on the performance of dual fuel diesel engine with hydrogen and LPG as secondary fuels", International Journal of Hydrogen Energy, 35, pp. 11918-11931.

[8]. Payri, F., Olmeda, P., Martín, J., and García, A., 2011, "A complete $0 \mathrm{D}$ thermodynamic predictive model for direct injection diesel engines", Applied Energy, 88, pp. 4632-4641.

[9]. Ganapathy, T., Murugesan, K. and Gakkhar, R.P., 2009, "Performance optimization of Jatropha biodiesel engine model using Taguchi approach", Applied Energy, 86, pp. 2476-2486

[10]. Stone, Richard, 1994, "Introduction to Internal Combustion Engines"-Second Edition, Society of Automotive Engineers, Inc., Warrendale, PA 
[11]. Ramos J.I., 1989, "Internal Combustion Engine Modeling", Hemisphere Publishing Corporation, New York.

[12]. Abu Nada, E., Al-Hinti, I., Akash, B. and Al-Sarkhi, A., 2006, "Thermodynamic analysis of spark-ignition engine: Effect of temperature dependent specific heats", International Communications in Heat and Mass Transfer, 33, pp. 1264-1272

[13]. Ozsoysal, O.A., 2006, "Heat loss as a percentage of fuel's energy in air standard Otto and Diesel cycles". Energy Conversion and Management, 47, pp. 10511062.

[14]. Rakopoulos C. D., Simulation and Analysis of a Natural Aspirated IDI Diesel Engine under Transient Conditions Comprising The Effect of Various Dynamic and Thermodynamic Parameters. Energy Convers. Mgmt, 1998; 39:465-484.

[15]. V.Ganesan, , 2013, "Computer Simulation of Compression-Ignition Engine Processes", Universities Press Private Limited, India.

\section{BIOGRAPHIES}

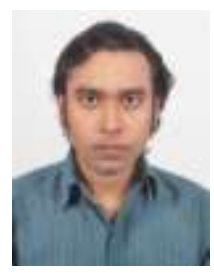

A. Samanta, Assistant Professor at Budge Budge Institute Technology. Kolkata. Did M.E from Jadavpur University.

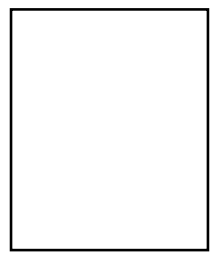

S. Kumar, PG Student of Automobile Engineering, Jadavpure University.

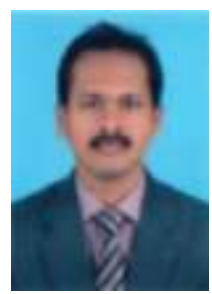

Dr. P. C. Roy, Assistant Professor at Jadavpur University, 